\title{
Influence of the Holland Vocational Aptitude Type on the Academic Achievement of Nursing Students
}

\author{
Mi Won Kim ${ }^{1}$ and Jeong-Mo Park ${ }^{2}$ \\ ${ }^{1}$ Dept. of Nursing, Sang-Myung University, Korea \\ kmw@smu.ac.kr \\ ${ }^{2}$ Dept. of Nursing, Kyung-In Women's University, Korea \\ jmpark@kiwu.ac.kr
}

\begin{abstract}
To identify the validity of Holland's vocational theory among nursing students and predict the factors influencing academic achievement and major satisfaction based on the Holland Vocational Aptitude Test. Methods: To identify vocational aptitude, we used the Holland's vocational aptitude test. To identify major satisfaction, we used the revised Korean version of a questionnaire based on the inventory. Major academic achievement was assessed using nursing students' report cards from their third and fourth years. The data were collected between November to December 2015 from students in three universities; 405 students' data were analyzed. Results: 1) Academic Achievement was highly congruent with Enterprise (E), Investigative (I), and Social (S) personality types and less congruent with Artistic (A) and Realistic (R) types. 2) Among the vocational achievement type points, Investigative (I) and Social (S) points had a positive influence on academic achievement, while Artistic (A) and Realistic $(R)$ points had a negative influence. Conclusion: Although Social types $(S)$ are presented as the nursing personality type, we found that people high on Enterprise (E) and Investigative (I) types also reported high satisfaction with their major and showed academic achievement as per Holland's codes; therefore, they can be seen as suitable personality types for nursing majors. Those who were Artistic (A) and Realistic (R) types showed low satisfaction and achievement; therefore, can be seen as unsuitable. These results can be used as a career guidance reference for prospective and current nursing students. Further research that confirms aptitude codes for nurses is required.
\end{abstract}

Keywords: Vocational, Personality, Holland's theory, Academic, Achievement, Nursing

\section{Introduction}

One of career counseling's oldest hypotheses is that individuals doing work that corresponds with their aptitude provides the most satisfaction and sense of accomplishment. Holland says that when individuals are in an environment that agrees with their aptitude type, they adapt well and rate their satisfaction with life as high, but people in an environment that does not agree with them are more likely to be maladjusted and are unlikely to receive recognition for their work [1][2]. Holland's theory of vocational personalities and work environments [3] has been recognized as valid through previous studies and was used as a foundation for the development of the Holland Codes, which are frequently used globally in career education, career counseling, and at career counseling centers [4]. However, Changgu [5] indicated that

Article history:

Received (June 24, 2016), Review Result (August 02, 2016), Accepted (September 24, 2016) 
we have to be cautious about recommending careers based on the Holland's interest test in South Korea because it is based on job interest codes that were developed by surveying people mainly living in the US. Maehyang and Heecheol [6] indicated that work seeking to understand vocational personality types in South Korea using Holland's theory is limited, and confirmed that codes given for each job in every test that applied Holland's theory were different in the Korean context, and if the codes were not applied properly, then it is possible to make mistakes when recommending jobs to those seeking counseling. This is significant as there is a need to confirm the validity of SIA-types (Social, Investigative, and Artistic) that are being proposed as nursing or nursing job environment codes [7] for South Korea's nursing practice environment and nursing studies.

Therefore, there is a need for studies to better understand the occupational personalities of South Korean nurses as well as studies that use nursing students as participants. This study uses nursing school students to confirm what kind of differences there are in academic achievement and satisfaction with one's major in nursing studies by using the six personality types from Holland's theory. The results of this study can be reflected in career counseling for prospective and current nursing students and used as baseline data for developing support programs for students with personality types that lead to difficulties in academic achievement.

\section{Related researches}

Holland identified six occupational environment and individual personality types (known as the acronym RIASEC): Realistic (R), Investigative (I), Artistic (A), Social (S), Enterprise (E), and Conventional (C). He also proposed the congruence hypothesis; when there is a congruence of individuals and environments - the more agreeable the individual's personality type and occupational environment, the higher their satisfaction and achievement. Holland noticed a correlation between the six personality types and designed a hexagonal form where similar characteristics are located closer and differing characteristics are located farther apart [3]. Holland's vocational theory, through previous research, is known for being able to predict student's career choices, development of interest, job satisfaction, and job or academic success [8], and is heavily utilized around the world. In South Korea as well, according to Changgyu [8], students find their aptitude type through career counseling following a standardization process to find the right job; these aptitude types are extensively used in personality tests given in university counseling rooms and at various school levels [4].

There have been a number of studies that investigate whether Holland's theory is suitable for the South Korean context, and while results generally support the theory, correlations have been lower than what Holland presented or results seemed to, in part, not support the theory's congruence [9]. Not many studies have investigated the congruency theory using students from a specific major, and there are no studies using nursing students as participants. These results generally report a positive relationship between vocational aptitude type congruence and major satisfaction, but they did not report any results that showed a correlation with academic performance. However, Holland vocational aptitude types have an influence on preferable teacher-learning methods or effective learning methods. For example, the Realistic-type is behavioral, so this type likes practical time, such as rote-teaching classes and assembling, rather than presentation classes, and have difficulty with cooperative tasks. The Social-type likes cooperative tasks more than competitive learning, and has a tendency to pay attention to detail or have analytical skills. Each type has methods that are more effective and that they prefer [10]. When looking at this, major and vocational personality congruence have an influence on academic achievement, but irrespective of aptitude congruence, we can 
predict that personality by school subject or learning method have an influence on academic achievement.

In the Dictionary of Holland Occupational Codes [7], nurses are presented as an SIA-type (Social, Investigative, and Artistic) occupation with Social-type being the representative type. Individual personality characteristics that correspond with people with Social-types are to see personal relationships as central, and have social and educational leadership skills, but lack mechanical and scientific skills, so the liberal arts are suitable for them [8]. Based on Holland's theory, students with characteristics most congruent with Social-type of the six types, were mere most satisfied with nursing school, had higher academic achievement, and we can predict that the complete opposite personality type, Realistic, would have the poorest major satisfaction and academic achievement.

\section{Objects of the study}

This study uses nursing students as participants to attempt to confirm the influence of occupational personality types and aptitude factor points on major satisfaction and academic achievement, to confirm the feasibility of Holland's vocational theory for nursing students.

The detailed purpose of our study is as follows:

First, to confirm the differences in academic achievement for each participant major satisfaction according to nursing student vocational aptitude type.

Second, to confirm the influence of individual vocational aptitude factor points on academic achievement.

\section{Methods and procedures}

\subsection{Study design}

This study is a descriptive investigation to confirm the validity of the hypothesis proposed by Holland's theory of vocational personalities and work environments for nursing students.

\subsection{Participants}

Before carrying out this study, we received approval from the Institutional Review Board (SMUIRB: AP-2015-002). We distributed questionnaires to 500 third and fourth year students that agreed to participate. The response rate of the questionnaire was $87.2 \%(\mathrm{~N}=436)$, with 31 of those sent in incomplete, leaving 405 respondents to the study.

\subsection{Measures}

\subsubsection{Holland vocational aptitude test}

To understand vocational personality types developed by Holland (1985) [11], we purchased and used the Holland ${ }^{\circledR}$ vocational aptitude test (for university students) modified by Changgyu and Hyeonee [1] through the company Insight. This tool is composed of 325 questions on personality aptitude, ability aptitude, vocational values, and high-low domains of job field aptitude.

\subsubsection{Satisfaction with one's major}

This tool is composed of 26 questions on general satisfaction, subject satisfaction, relationship satisfaction, and perception satisfaction developed by Hyesuk [2] and based on 
the major satisfaction questionnaire developed by Braskamp, Wise, and Hengstler [12]. Each question was rated on a scale of 1 'not satisfied at all' to 5 'very satisfied.'

\subsubsection{Academic achievement in one's major}

We collected report cards in order to reflect real achievement to determine academic achievement in the major, and reflected the grades of third year, sixth semester students and fourth year, eighth semester students. Overall academic achievement reflected overall average grades for related classes, and academic achievement by nursing student subject type was calculated by sorting by on-site practical classes that demand application of knowledge, attitude, and theory of knowledge-led major theory classes. Grades were converted into points as follows: $\mathrm{A}+$ is $4.5, \mathrm{~A}$ is $4.0, \mathrm{~B}+$ is $3.5, \mathrm{~B}$ is $3.0, \mathrm{C}+$ is $2.5, \mathrm{C}$ is $2.0, \mathrm{D}+$ is $1.5, \mathrm{D}$ is 1 and $\mathrm{F}$ is 0 .

\subsection{Data collection}

Data were collected from November 102015 to December 20 2015. Researchers explained the study's purpose and meaning to the participants and started the survey after receiving letters of consent. The surveys took 50-60 minutes.

\subsection{Statistical procedures}

Collected data were analyzed using the SPSS 21.0 statistics program and the level of significance was set to 0.05 . The career personality type was set as one letter for the code that participants received the highest point value, designated as R, I, A, S, E and C. The KruskalWallis test, which is a non-parametric test, was used to determine the difference in satisfaction in one's major and academic achievement according to participants' general characteristics and the Mann Whitney U-test was used to conduct post-hoc analysis. The influence of general characteristics, personality factor points, and satisfaction with one's major on academic achievement was assessed using hierarchical regression analysis.

\section{Results}

\subsection{Vocational personality type by academic achievement and satisfaction in one's major}

1) There was a significance difference $(\mathrm{p}<.001)$ in academic achievement found through total average score by personality type, with $\mathrm{E}, \mathrm{I}$, and S-types receiving high scores and A and R-types receiving significantly lower scores.

2) There was a significant difference $(\mathrm{p}<.001)$ in achievement in one's major subject, with I and E-types being the highest and A and R-types being significantly lower.

3) There was a significance difference $(\mathrm{p}<.001)$ in on-site practical achievement by personality type with E-types being the highest and $\mathrm{R}$ and A-types being significantly lower.

4) There was a significant difference $(p=.005)$ seen in satisfaction in one's major by personality type, with $\mathrm{E}, \mathrm{S}$, and I-types being the highest, and $\mathrm{C}$ and A-types being significantly lower.

\subsection{The influence of vocational personality factor points and satisfaction in one's major on academic achievement}


The first step was just the general variables, in the second step RIASEC factor points were added, and in the third step, satisfaction with one's major points were added to analyze their influence on academic achievement. The results are as follows.

1) We found an influence of $3.6 \%$ in the first step ( $p=.002), 11.3 \%$ in the second step $(p=.000)$, and $12.9 \%$ in the third step $(p=.005)$ on the total average achievement. In the second step I and S points had a significant positive influence $(\beta=3.52, p=.002, \beta=3.15$, $p=.002)$, while A points had a negative influence. $(\beta=-3.53, p=.002)$

2) Major theory achievement was $4.7 \%$ in the first step ( $p=.000), 11.1 \%$ in the second step $(p=.000)$, and $11.3 \%$ in the third step $(p=.141)$. In the second step, Investigative points had the largest influence. $(\beta=3.4, p=.002)$

3) On-site practical achievement was $3.9 \%$ in step $1(p=.001), 9.0 \%$ in step $2(p=.001)$, and $9.0 \%$ in step $3(p=.371)$. In step 2 , S points $(\beta=2.80, p=.005)$ and $E$ points $(\beta=2.64$, $p=.00)$ had a significant influence.

\section{Conclusions}

1) In the Holland's Dictionary of Occupational Codes, the representative personality type for nurses is presented as Social (S), but the results of our study did not completely agree with this.

2) The personality types Enterprise (E), Social (S), and Investigative (I) all had high satisfaction in one's major, while Conventional (C) and Artistic (A) were low.

3) The personality types Enterprise (E), Investigative (I), and Social (S) all had high academic achievement, while Artistic (A) and Realistic (R), were low.

4) We can see that not only Social (S) types but also Enterprise (E), and Investigative (I) are suitable types for nursing majors, as they all had high satisfaction in one's major and academic achievement.

5) Artistic (A), and Realistic (R) can be seen as unsuitable for nursing majors as they both had low satisfaction and academic achievement.

6) Irrespective of occupational personality types, Investigative factor points (I) and Social factor point $(S)$ had a positive influence on academic achievement and Artistic factor points (A) and Realistic-type points (R) had a negative influence on academic achievement.

7) It is necessary to find methods for helping adjustment and improve their academic achievement in Artistic-type (A) and Realistic-type (R) nursing students.

8) These results can be referred to while providing career counseling to students before they enter university and for current nursing students.

9) Further research that confirms this study's results and aptitude types of university nursing students and nurses is required.

\section{References}

[1] H. N. Ahn and C. G. Ahn, "Manual for holland career personality inventory," Inpsyt, Inc, Korea: Seoul, (2016)

[2] H. S. Ha, "A study of department satisfaction and school satisfaction of undergraduate students," Master's thesis, Seoul National University, Seoul, (2000)

[3] J. L. Holland, "The vocational preference inventory: counseling psychologists," Palo Alto, CA, (1997)

[4] H. J. Kim, "Applicability of Holland's vocational interest model for Korean university students," The Korea Journal of Counseling, vol.8, no.2, pp.603-619, (2007) 
Influence of the Holland Vocational Aptitude Type on the Academic Achievement of

Nursing Students

[5] C. G. Heo, "Development of Holland vocational interest inventory (short form) and investigation of Holland's hypothesis," Korean Journal of Industrial and Organizational Psychology, vol.4, pp.695-718, (2011)

[6] M. H. Hwang, and H. C. Choi, "Convergent validity across Korean Holland code classifications," Korean Journal of Counseling, vol.13, no.2, pp.995-1012, (2012)

[7] H. N. Ahn and C. G. Ahn, "Holland Occupational Codes Book," Inpsyt Seoul, (2014)

[8] C. K. Ahn, "A study for the standardization of the career exploration inventory," Korean Journal of Counseling and Psychotherapy, vol.8, no.1, pp.169-199, (1996)

[9] W. S. Cho, "Correlation between major satisfaction and academic achievement in accordance with majorinterest correspondence of the university students," Master's thesis, Daejin University, Kyunggi, Korea, (2008)

[10] Y. H. Choi, and M. Seo, H., "The Relationship between vocational interest types, Intelligence, and academic achievement of engineering students," Korean Journal of General Education, vol.4, no.1, pp.199-217, (2010)

[11] J. L. Holland, Editors, "The Self-Directed search: professional manual," Odessa, FL, (1985)

[12] L. A. Braskamp, S. L. Wise, and D. D. Hengstler, "Student satisfaction as a measure of departmental quality," Journal of Educational Psychology, vol.71, no.4, (1979) 